Angie Schneider

\title{
Vertragsanpassung im bipolaren Dauerschuldverhältnis
}

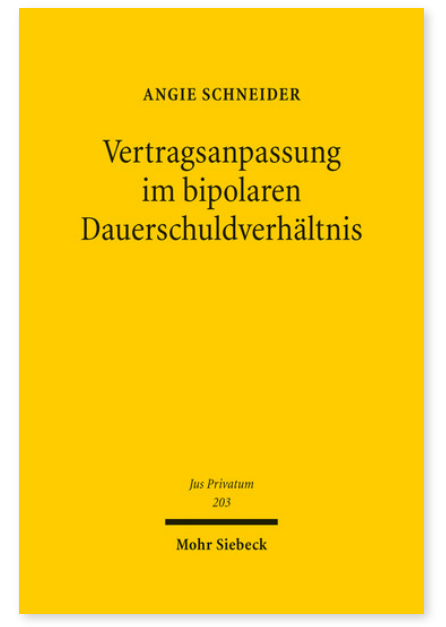

2016. XVIII, 479 Seiten. JusPriv 203

ISBN 978-3-16-154130-8

DOI 10.1628/978-3-16-154130-8

eBook PDF 134,00€

ISBN 978-3-16-154067-7

Leinen $134,00 €$
Anpassungsregelungen geben den Vertragsparteien die Möglichkeit, ein Vertragsverhältnis geänderten Bedingungen anzupassen. In Dauerschuldverhältnissen erweisen sich derartige Anpassungsbestimmungen als unverzichtbar. Es existieren jedoch nahezu keine gesetzlichen Anpassungsregelungen, die auf alle Arten von Dauerschuldverhältnissen anwendbar sind. Darüber hinaus werden vertraglich vereinbarte Anpassungsbestimmungen keinen einheitlichen und transparenten Anforderungen unterworfen, weder seitens des Gesetzgebers noch der Rechtsprechung. Es fehlt somit an der Einheitlichkeit von Vertragsanpassungsregelungen. Angie Schneider unternimmt erstmalig den Versuch, generelle Maßstäbe für alle im Bürgerlichen Schuldrecht geregelten bipolaren Dauerschuldverhältnisse unter Einschluss des Arbeitsverhältnisses aufzustellen.

Angie Schneider Geboren 1979; Studium der Rechtswissenschaft in Düsseldorf und Köln; 2004 erstes Staatsexamen; Referendariat im OLG-Bezirk Düsseldorf; 2006 Promotion; 2008 zweites Staatsexamen; 2014 Habilitation; seit 2008 Akademische Rätin auf Zeit am Institut für deutsches und europäisches Arbeits- und Sozialrecht, Universität zu Köln.

Jetzt bestellen:

https://mohrsiebeck.com/buch/vertragsanpassung-im-bipolaren-dauerschuldverhaeltnis-9783161541308?no_cache=1 order@mohrsiebeck.com

Telefon: +49 (0)7071-923-17

Telefax: +49 (0)7071-51104 